\title{
DETERMINATION OF SIMULTANEOUS SULFAMETHOXAZOLE AND TRIMETHOPRIM BY ULTRAVIOLET SPECTROPHOTOMETRY WITH MEAN CENTERING OF RATIO SPECTRA
}

\author{
MUCHLISYAM*, PARDEDE TR, SATIAWAN R \\ Department of Pharmaceutical Chemistry, Faculty of Pharmacy, Universitas Sumatera UtaraPadang Bulan, Medan, Indonesia. \\ Email: muchlisyam@usu.ac.id
}

Received: 07 March 2018, Revised and Accepted: 25 March 2018

\begin{abstract}
Objective: Mean Centering of Ratio Spectra is an analytical method of quantitative spectrophotometric analysis for binary mixture in tablet. The purpose of this study is a determination of sulfamethoxazole (SLF) and trimethoprim (TRM) mixture by ultraviolet spectrophotometry with MCR.

Methods: Absorption spectra of each drug were recorded and divided by the corresponding concentration of divisor, and the ratio spectra were then mean centered. SLF and t TRM concentrations were determined from calibration graphs by measuring at obtained maximum wavelengths 256 nm for SLF and $288 \mathrm{~nm}$ for TRM.

Result: The result determination of SLF and TRM content in tablet S was $103.31 \pm 0.34 \%$ and $96.588 \pm 2.13 \%$, respectively, result of validation method was fulfilled, calibration graph of each SLF and TRM were obtained by plotting the mean center values versus corresponding concentrations and the regression equations of SLF and TRM were obtained.
\end{abstract}

Conclusion: The determination simultaneous by ultraviolet spectrophotometry of MCR was found to be accurate, precise, simple, and rapid method and can be used for SLF and TRM mixture.

Keywords: Sulfamethoxazole, Trimethoprim, Ultraviolet spectrophotometry method, Mean centering of ratio spectra, Validation.

(C) 2018 The Authors. Published by Innovare Academic Sciences Pvt Ltd. This is an open access article under the CC BY license (http://creativecommons. org/licenses/by/4. 0/) DOI: http://dx.doi.org/10.22159/ajpcr.2018.v11s1.26569

\section{INTRODUCTION}

The combination of sulfamethoxazole (SLF) and trimethoprim (TRM) is one of a drug combinations that are synergistic and functioning as bactericidal, especially for the treatment of respiratory infections, bladder infections, and gastrointestinal infections also skin and soft tissue infections [1]. This combination pharmaceutical preparation is available at a 5:1 ratio in various doses. SLF with a chemical name N.1- (5-methyl-3-isoxazole) sulfanilamide is sulfonamide group [2,3]. It is used for bacterial infections such as urinary tract infections, bronchitis, and prostatitis and is effective for Gram-negative and positive bacteria, with slower absorption and excretion, which is commonly used for bladder infections and systemic infections, but the use of these drugs caused

by the formation of crystalluria is more common because of the high acetylation percentages, and these drugs are commonly used in the form of fixed combinations with TRM [1]. TRM with the chemical name 2,4-diamino-5-(3,4,5-trimethoxybenzyl) pyrimidine is a pimalethamine derivative from antimalarial drug that has antiprotozoal and bacteriostatic functions $[2,3]$. The mechanism of the action of TRM is similar to sulfonamides based on the inhibition of reduction of DHFA to THFA through blockade reductase so that bacterial DNA synthesis fails [1]. The Chemical structure can be shown Vargous literatures have formulate the determination of the concentration of cotrimoxazole mixture, using the method of high-performance liquid chromatography (HPLC) using aqueous phases:acetonitrile: triethylamine(1400:400:2), ultraviolet spectrophotometry by zerocrossing method using $0.1 \mathrm{~N} \mathrm{HCl}$ solvent, and ultravioletspectrophotometry simultaneously using $0.1 \mathrm{~N} \mathrm{NaOH}$ as a solvent with a wavelength of $256 \mathrm{~nm}$ for SLF and $287 \mathrm{~nm}$ for TRM [2-5]. Spectrophotometric method has been developed by Afkhami and Bahram which is mean centering of ratio spectra (MCR) method using the calculation of regression equation based on amplitude and calculation of each amount using divisor principle that can be used at simultaneous amount determination of binary and ternary mixture without separation steps. This method has supremacy than ordinary ultraviolet spectrophotometry and derivative spectrophotometry because without going through the derivatization process [6]. Some researchers have used MCR methods on the determination of mixed drugs such as thiomersal, lidocaine, and phenylephrine, ternary mixture of amlodipine, aliskiren, and hydrochlorothiazide, mixtures of diclofenac and sodium pantoprazole in tablets, gatifloxacin and dexamethasone in tablets, analysis of five-component mixture in drug analysis, salicylic acid and benzoic acid in fruit joice samples [7-12].The aim of this research is to a determination of SLF and TRM in tablet pharmaceutical form with $0.1 \mathrm{~N}$ $\mathrm{NaOH}$ as a solvent by MCR methods.

\section{METHODS}

\section{Apparatus}

A Shimadzu model 1800 double beam ultraviolet (UV)-visible spectrophotometer with spectral bandwidth of $1 \mathrm{~nm}$ and wavelength accuracy of $0.1 \mathrm{~nm}$ (at $656.1 \mathrm{~nm}$ ) was used to measure absorbance of all the solutions. Spectra automatically obtained by UV-probe system software and MATLAB version 9.0 were used in the study.

\section{Materials}

Pharmaceutical grade of SLF supplied by the Food and Drug Regulatory Agency of Indonesia (claimed purity of 100.31\%), TRM supplied by the Food and Drug Regulatory Agency of Indonesia (claimed purity of $99.90 \%$ ), analytical ethanol, and $\mathrm{NaOH}$ were used throughout these experiments. The pharmaceutical Sanprima ${ }^{\circledR}$ tablet (S Commercial Tablet) contained $400 \mathrm{mg}$ of SLF and $80 \mathrm{mg}$ of TRM per tablet was manufactured by PT Sanbe Farma, Bandung, Indonesia.

\section{Preparation of standard solutions}

An accurately weighed standard of $50 \mathrm{mg}$ SLF and $50 \mathrm{mg}$ TRM powder and each of them transferred to $50 \mathrm{ml}$ volumetric flasks and dissolved by $15 \mathrm{ml}$ of $70 \%$ ethanol and mixture. The volume was made up to mark with $0.1 \mathrm{~N} \mathrm{NaOH}$ to achieve a concentration of $1000 \mu \mathrm{g} / \mathrm{ml}$ of SLF and $1000 \mu \mathrm{g} / \mathrm{ml}$ TRM (standard solution I). Then, each of standard solution I was taken $6.25 \mathrm{ml}$ and transferred to separated $100 \mathrm{ml}$ volumetric flasks, to achieve $251 \mu \mathrm{g} / \mathrm{ml}$ of SLF and $251 \mu \mathrm{g} / \mathrm{ml}$ TRM (standard working II). 
Spectral characteristic of SLF and TRM

The absorption spectrum of ultraviolet spectrophotometric is one of the characteristics of the analysis of a drug [13] meanwhile another characteristics such as solubility and qualitative identification with spectral absorption. In the analysis of SLF and TRM mixtures, an examination of the absorption spectrum to be developed is the maximum wavelength that is the start of the MCR methods.

\section{Construction spectra absorption curve of SLF}

Pipetted of $1.6 \mathrm{~mL}$ SLF standard working II solution, then transferred to a $25 \mathrm{~mL}$ volumetric flask. Dilute it using $0.1 \mathrm{~N} \mathrm{HCl}$ to the line of volumetric flask, then homogenized to get the concentration of $6.45 \mu \mathrm{g} / \mathrm{mL}$, and measured the absorbance from $200 \mathrm{~nm}$ to $400 \mathrm{~nm}$.

\section{Construction spectra absorption curve of TRM}

Pipetted $1.75 \mathrm{~mL}$ of TRM standard working solution then transferred to a $25 \mathrm{~mL}$ volumetric flask. Dilute it using $0.10 .1 \mathrm{~N} \mathrm{NaOH}$ until the line of volume TRMc flask, then homogenized to get the concentration of $17.57 \mu \mathrm{g} / \mathrm{mL}$, and measured the absorbance from $200 \mathrm{~nm}$ to $400 \mathrm{~nm}$.

Construction of spectral characteristics of SLF and TRM in mixture Pipetted $1 \mathrm{~mL}$ SLF's working solutions and pipetted $2 \mathrm{~mL}$ from TRM's working solutions then mixed and measured the absorbance from $200 \mathrm{~nm}$ to $400 \mathrm{~nm}$.

\section{Construction of absorbance spectrum mixture of SLF and TRM}

Pipetted of $1.0 \mathrm{~mL}, 1.5 \mathrm{~mL}, 2.0 \mathrm{~mL}, 2.5 \mathrm{~mL}, 3.0 \mathrm{~mL}$ SLF working solutions, respectively, then transferred each to different $25 \mathrm{~mL}$ volume TRMc flasks, then pipetted $4.2 \mathrm{~mL}, 6.3 \mathrm{~mL}, 8.3 \mathrm{~mL}, 10.4 \mathrm{~mL}$, and $12.5 \mathrm{~mL}$ TRM parent stock solutions, and transferred each to the SLF solution above into $50 \mathrm{ml}$ volume TRMc flask and diluted them using $0.1 \mathrm{~N} \mathrm{NaOH}$ until the line of volumetric flask, then homogenized to get their own absorbance.

\section{Ratio spectra of SLF absorbance with MCR methods}

The SLF and TRM mixture absorbance spectrum was manipulated with UV Probe 2.42 software by dividing $17.57 \mu \mathrm{g} / \mathrm{mL}$ TRMs to get the first ratio spectra as data set. Data set was printed and exported to Microsoft Excel for mean centered with the help of Matlab R2009a.

\section{Ratio spectra of TRM absorbance with MCR method}

The SLF and TRM mixture absorbance spectrum was manipulated with UV Probe 2.42 software by dividing $6.557 \mu \mathrm{g} / \mathrm{mL}$ SLF's which was to get the first ratio spectra as data set. Data set was printed and exported to Microsoft Excel for mean centered with the help of Matlab R2009a.

\section{Construction of calibration curve}

The calibration curve of ultraviolet spectrophotometry, on the $\mathrm{X}$-axis expressing the wavelength and on the Y-axis, represents the absorbance of a spectrum. However, on the MCR method, that the $\mathrm{Y}$ axis is the amplitude in the form of the result data after the mean centered with the help of Matlab software, which the process is calculated by calculating the result of measurement of the spectrums obtained from the disTRMbution of spectral absorbance data which has been analyzed at each Point wavelength using UV Probe software 2.42 and obtained absorbance ratio. Then calculated by Matlab software can result the average value of the absorbance value of the ratio at each wavelength point. The result of this average value subtracted on the absorbance ratio is the MC value and is called the amplitude and plotted by the wavelength, and the regression equation is obtained $[8,11-13]$.

\section{Calibration curve of SLF and TRM using MCR method}

Mean-centered value (amplitude) from the first ratio spectra at $271 \mathrm{~nm}$ for SLF and $257 \mathrm{~nm}$ for TRM was obtained, then calculated the regression, and plotted it in a concentration versus amplitude graph using Matlab R2009a [14-18]

\section{Linearity}

Standard solution of SLF and TRM for absorption spectrum was made and measured at the selected wavelength point $(271 \mathrm{~nm}$ for SLF and $257 \mathrm{~nm}$ for TRM). The amplitude values of both active substances were determined using the regression equation for each component at its own selected wavelength [14-17].The obtained regression equation general formula is as follows:

$\mathrm{Y}=\mathrm{ax}+\mathrm{b}$

Note:

$\mathrm{y}=$ Amplitude

$\mathrm{a}=$ Slope

$\mathrm{x}=$ Concentration $(\mu \mathrm{g} / \mathrm{mL})$

$\mathrm{b}=$ Constant

Relative standard deviation (RSD) test

Formula for RSD calculation:

$\mathrm{RSD}=\frac{\mathrm{sd}}{\overline{\mathrm{X}}} \times 100 \%$

Limit of detection (LOD) and limit of quantification (LOQ) test According to the absorbance at analysis wavelength, LOD and LOQ were counted.

$S D=\sqrt{\frac{\sum(Y-Y i)^{2}}{n-2}}$

$$
\begin{aligned}
& \mathrm{LOD}=\frac{3.3 \times \mathrm{SD}}{\text { slope }} \\
& \mathrm{LOQ}=\frac{10 \times \mathrm{SD}}{\text { slope }}
\end{aligned}
$$<smiles>Cc1cc(NS(=O)(=O)c2ccc(N)cc2)no1</smiles><smiles>COc1cc(Cc2cnc(N)nc2N)cc(OC)c1OC</smiles>

Fig. 1: The chemical structure of struktur sulfamethoxazole (a) and trimethoprim (b) 


\section{RESULTS AND DISCUSSIONSO.}

\section{Determination of maximum absorption spectrum}

The determination of the maximum absorption spectrum of SLF is at a concentration of $6.45 \mathrm{mcg} / \mathrm{ml}$ and concentration of $17.57 \mathrm{mcg} / \mathrm{ml}$ for TRM. Determination of maximum absorption spectrum is measured at wavelength 200-400 $\mathrm{nm}$. The maximum absorption spectrum of SLF and TRM can be seen in Figs. 2 and 3.
Based on Fig. 2, it can be seen that the wavelength of maximum absorption for SLF is at $256 \mathrm{~nm}$. This is accordance to the literature which states that the maximum absorption for SLF in an alkaline solution is $256 \mathrm{~nm}$ [13].

Based on Fig. 3, it can be seen that the wavelength of maximum absorption for TRM is at $288 \mathrm{~nm}$. While in the literature that the absorption of TRM in base solution is $287 \mathrm{~nm}$, but this is still allowed because the wavelength difference is still below $2 \mathrm{~nm}$ [13].

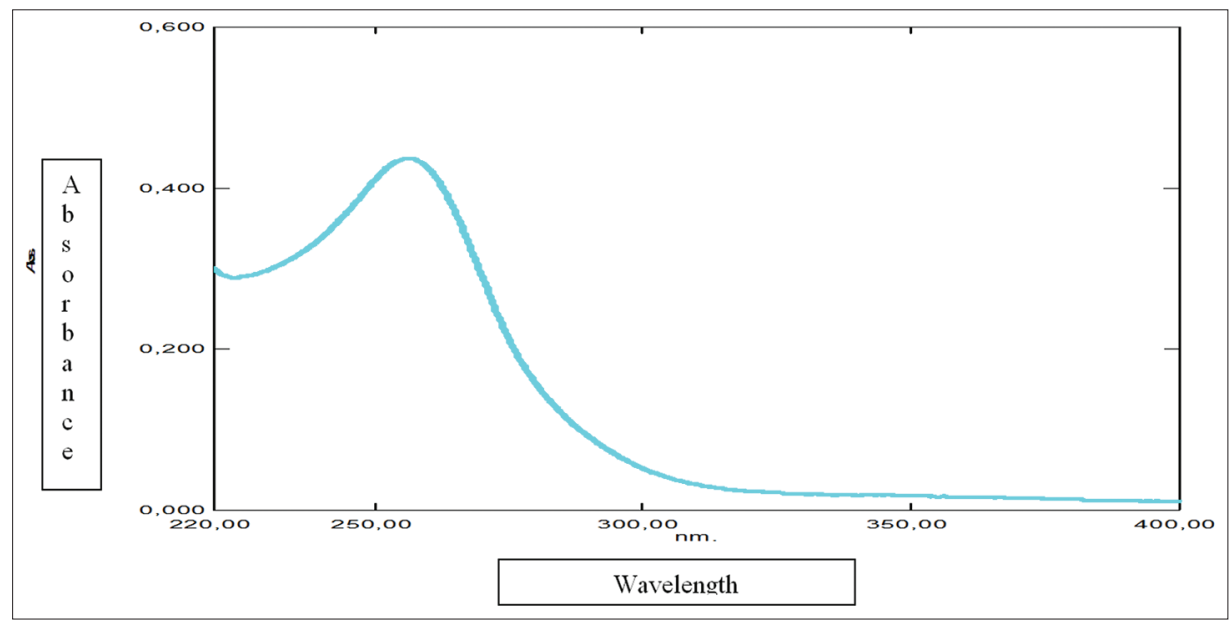

Fig. 2: Maximum absorption spectrum of sulfamethoxazole $(6.55 \mathrm{mcg} / \mathrm{ml})$ at $256 \mathrm{~nm}$

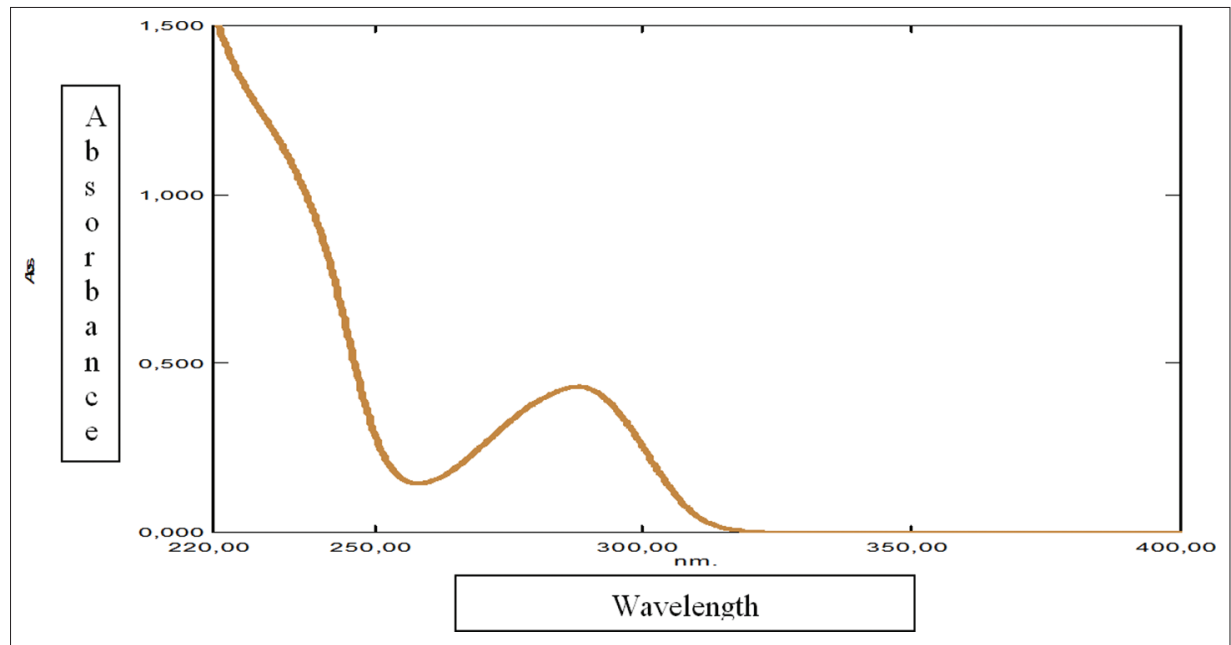

Fig. 3: Maximum absorption spectrum of trimethoprim $(17.57 \mathrm{mcg} / \mathrm{ml})$ at $288 \mathrm{~nm}$

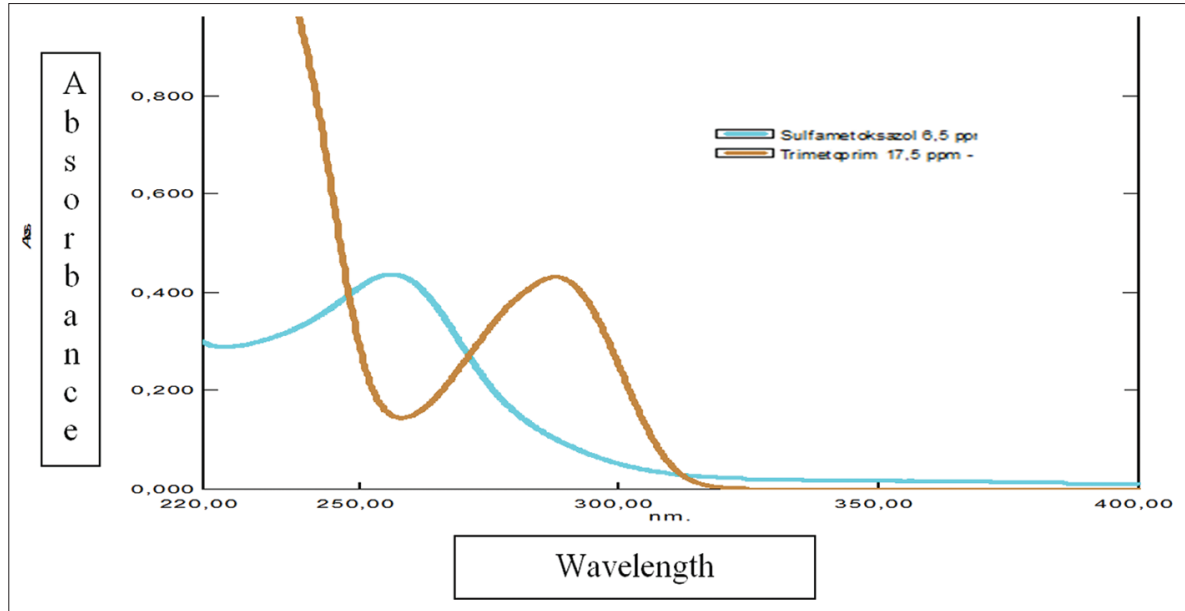

Fig. 4: Maximum absorption overlap spectrum of sulfamethoxazole and trimethoprim 
Based on Fig. 4, it can be seen that the maximum absorption spectrum of SLF and TRM overlap each other so that classic spectrophotometry absorption cannot be performed because the result absorbance has been interfering with each other component [14].

Absorption spectrum result of standard mixture of SLF and TRM Absorption spectrum of standard mixture of SLF and TRM is shown in Fig. 5 .
In Fig. 5, it can be seen that the absorption spectrum of the standard mixture of SLF and TRM is made with concentration of $8.2 \mathrm{mcg} / \mathrm{ml}$ for SLF and $17.8 \mathrm{mcg} / \mathrm{ml}$ for TRM. The mixed spectrum produces each different shapes with the spectrum of SLF and TRM since the absorption spectrum is a combination of the both spectrums.

Ratio absorption spectrum result of SLF and TRM

The ratio absorption spectra of the SLF and TRM are shown in Figs. 6 and 7.

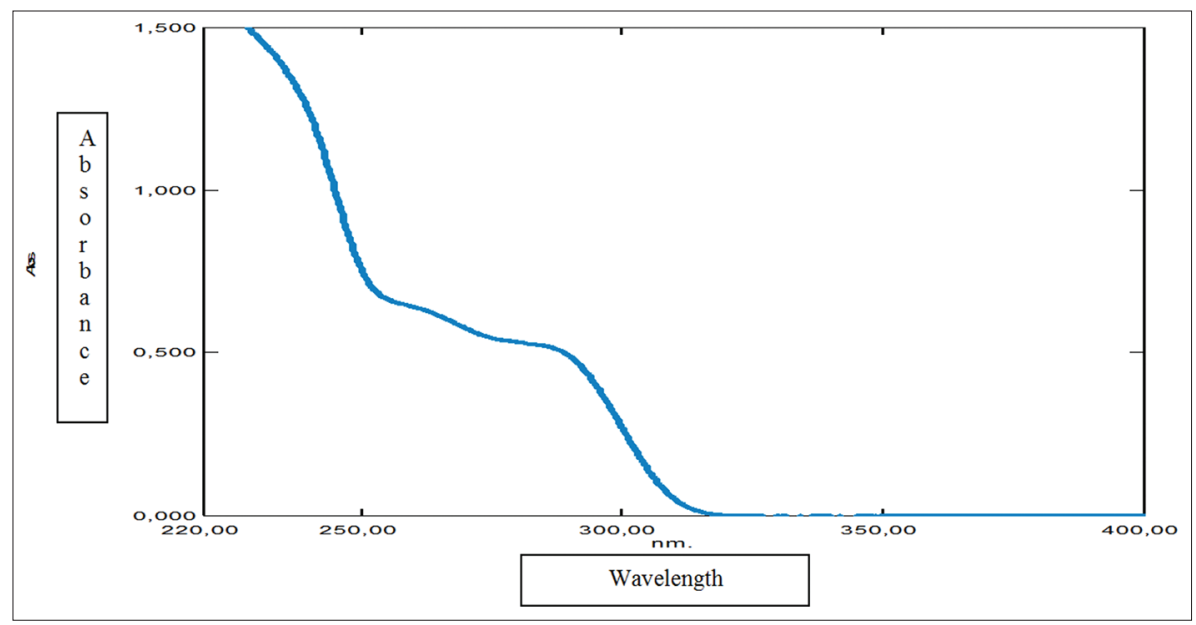

Fig. 5: Absorption spectrum of standard mixture of sulfamethoxazole and trimethoprim

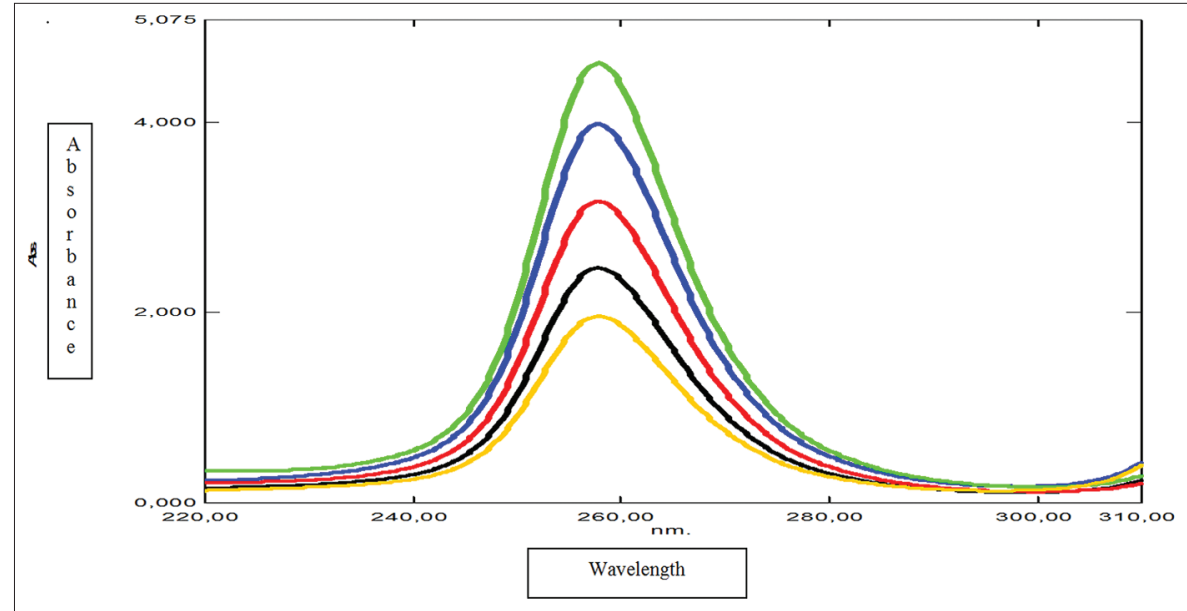

Fig. 6: Ratio absorption spectrum of sulfamethoxazole with $17.57 \mathrm{mcg} / \mathrm{ml}$ trimethoprim as a divisor

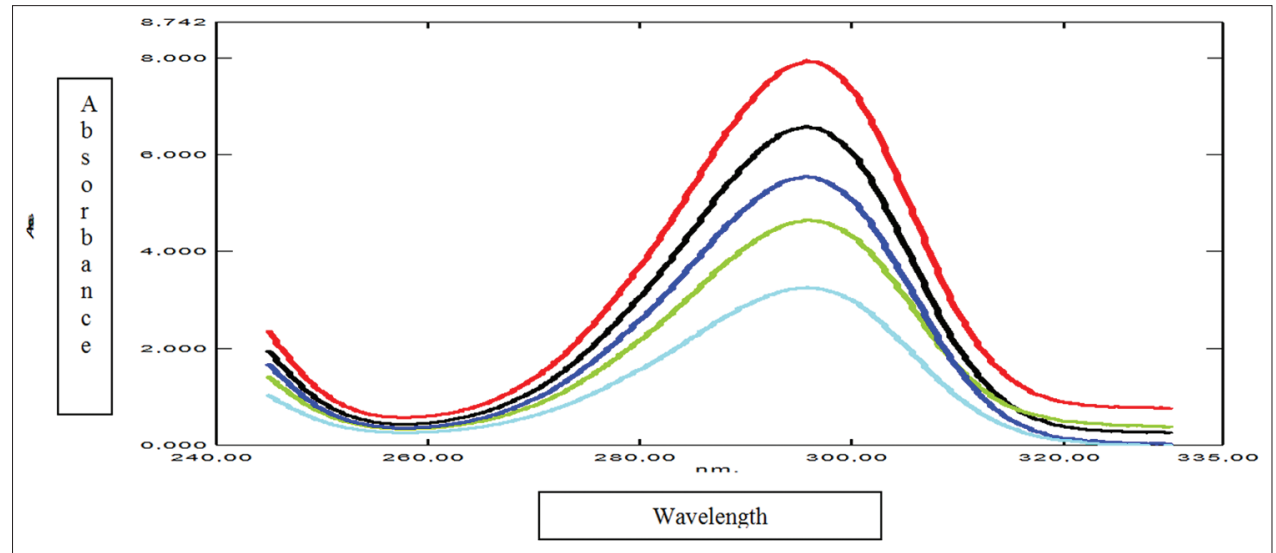

Fig.7: Ratio absorption spectrum of trimethoprim with $6.55 \mathrm{mcg} / \mathrm{ml}$ sulfamethoxazole as a divisor 
The spectrum of the SLF ratio was made by dividing the SLF absorption spectrum at various concentrations with the TRM concentration of $17.57 \mathrm{mcg} / \mathrm{ml}$ concentration as the divisor, and the TRM ratio spectrum was made by dividing the TRM uptake spectra at various concentrations with the SLF spectrum of concentration of $6.55 \mathrm{mcg} / \mathrm{ml}$ as the divisor.

MCR of SLF, TRM, and overlapping spectrum

MCR spectra of SLF, TRM, and overlapping spectra are shown in Figs. 8-10.
The absorption spectrum is done by MCR which is a continuation of spectrum ratio with the help of MATLAB software. That the spectrum ratio has been input into MATLAB software and find the MC value of each spectrum. In Fig. 11, it can be seen that the overlapping spectra of the absorbance of each drug components have not been affected by the other components so that the absorbance of each spectrum has already stated the absorbance of the component itself.

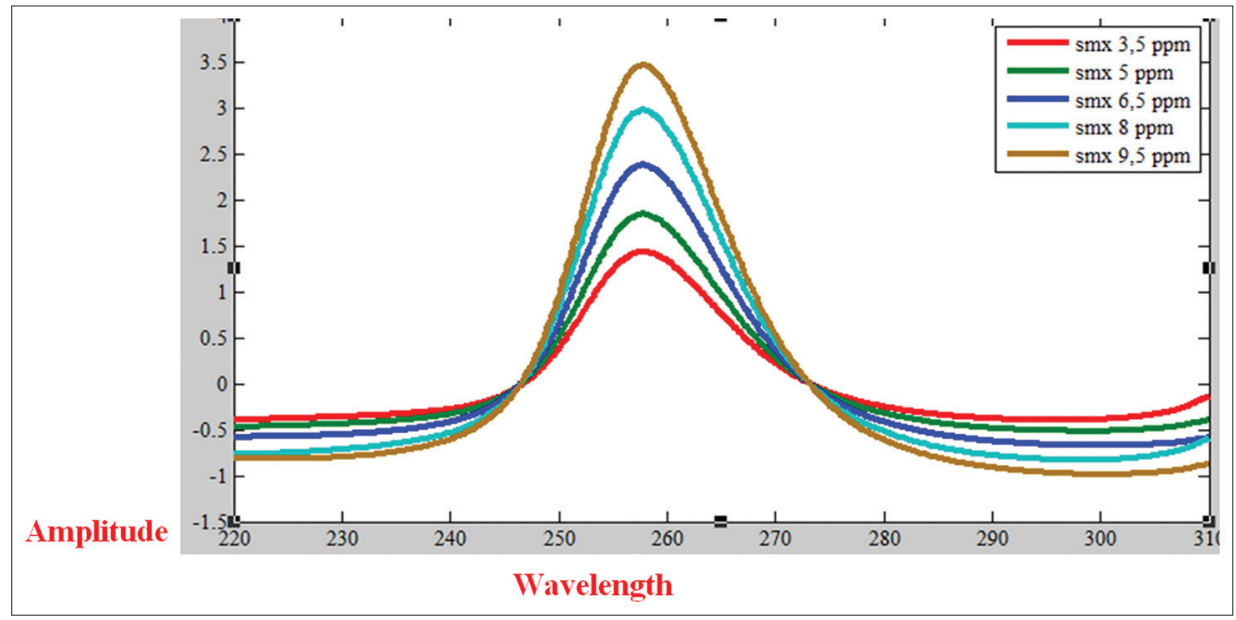

Fig. 8: Mean centering of ratio spectra of sulfamethoxazole

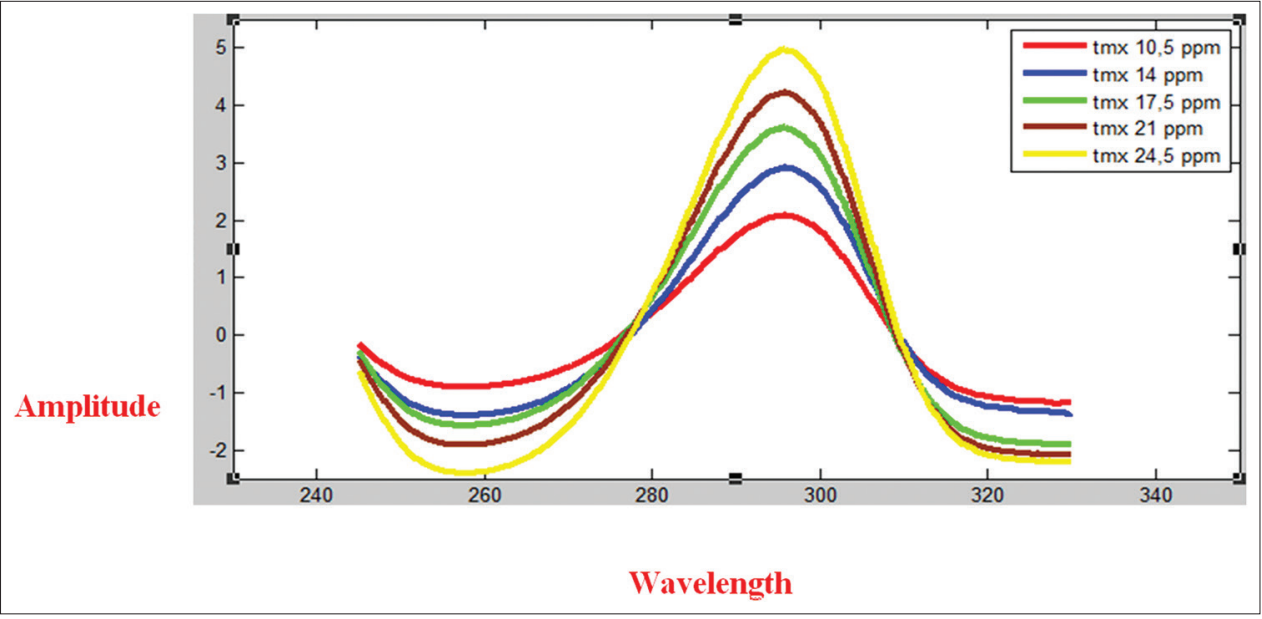

Fig. 9: Mean centering of ratio spectra of trimethoprim

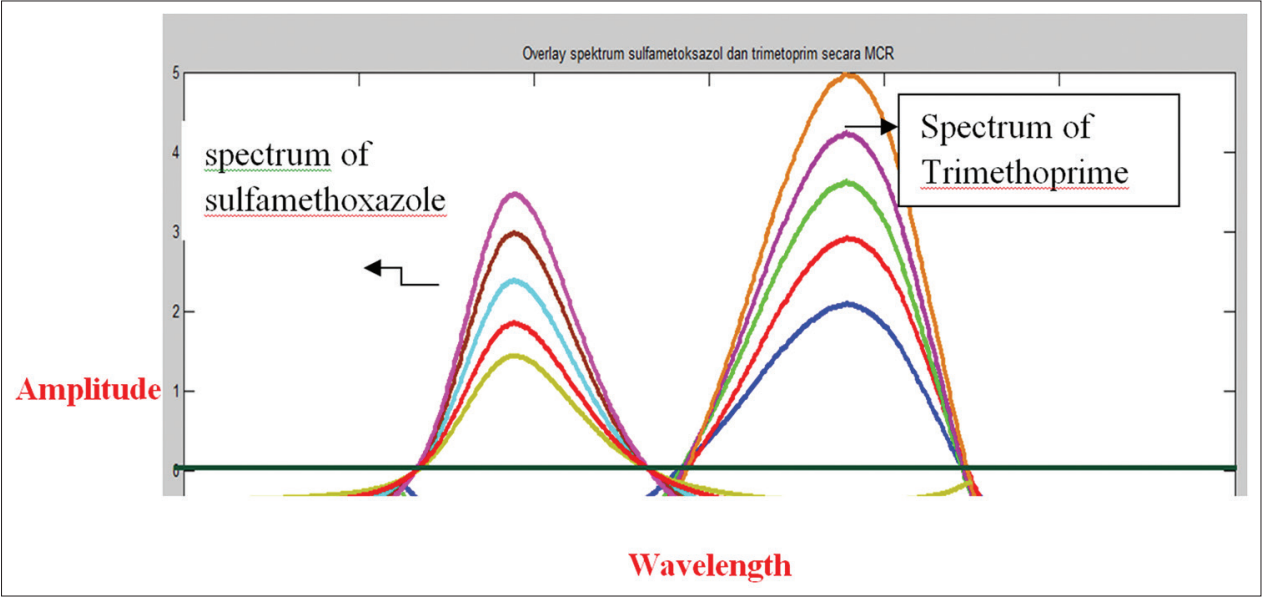

Fig. 10: Spectrum overlap sulfamethoxazole and trimethoprim by mean centering of ratio spectra 
The Fig. 10 above that spectrum was obtained from the absorbance data of the absorption spectrum analyzed divided by the determined divisor using UV Probe 2.42 software so that the ratio absorbance result was obtained so that the ratio absorbance result was obtained. The next stage is to find the average of each absorbance value of the ratio that has been obtained, and the value of MC obtained using MATLAB Software (MathWorks).

\section{Calibration curve creation by MCR}

The calibration curve MCR is done by plotting the MC value obtained with the concentration of each raw, then calculated the regression equation and correlation coefficient of SLF and TRM. The SLF regression equation used in this study is $y=36297 x+0.05463$, and TRM regression equation is $y=0.20340 x+0,00573$. The value of $r$ arithmetic compared with $r$ table with $99 \%$ confidence level with df 4 is 0.9172 . The value of $r$ arithmetic is greater than $r$ table, so it shows good linearity.

\section{Method validation}

Validation parameters tested were accuracy, precision, LOD, and LOQ. Accuracy is expressed by \% recovery determined by standard addition method.In this study, the validation test was done using S commercial tablet sample.

The recovery rate requirement (\% recovery) is $98-102 \%$, and the median recovery rate on tablet S is $101.24 \%$ for SLF and $100.89 \%$ for TRM. RSD has fulfilled the requirement with RSD value $<2 \%$, i.e., $0.41 \%$ for SLF and $0.96 \%$ for TRM. Limit detection and limit of quantitation of SLF were $0.5569 \mathrm{mcg} / \mathrm{ml}$ and $1.8896 \mathrm{mcg} / \mathrm{ml}$, respectively, while for TRM were $0.8083 \mathrm{mcg} / \mathrm{ml}$ and $2.6793 \mathrm{mcg} /$ $\mathrm{ml}$, respectively.

Based on these results, the analytical method of mixed SLF and TRM with ultraviolet spectrophotometry on MCR has fulfill the requirements of method validation.

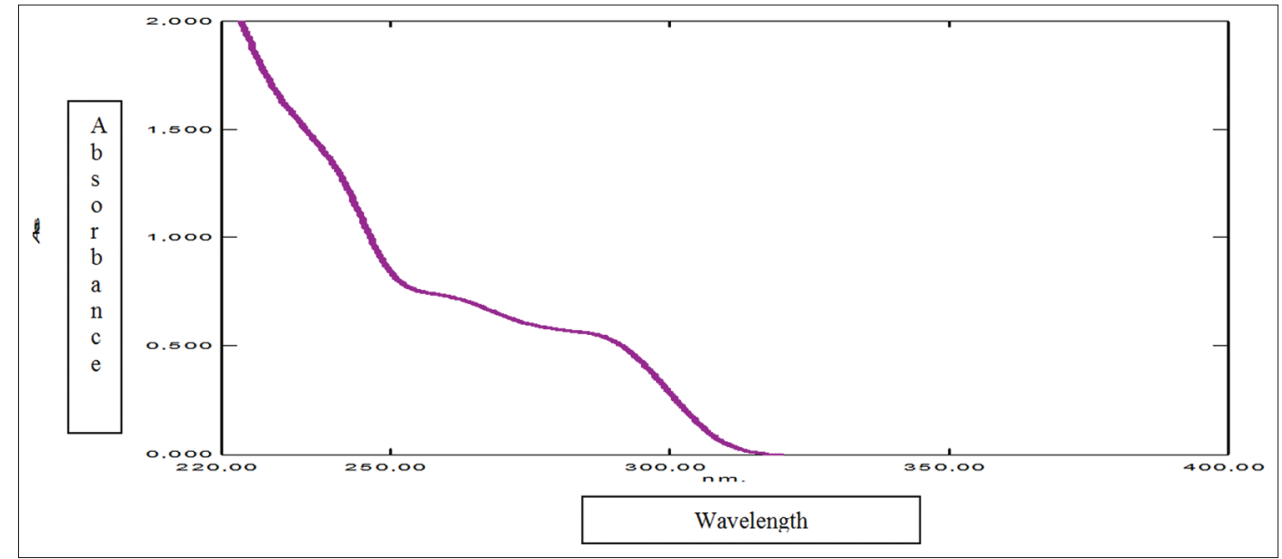

Fig. 11: Spectrum of S commercial tablet

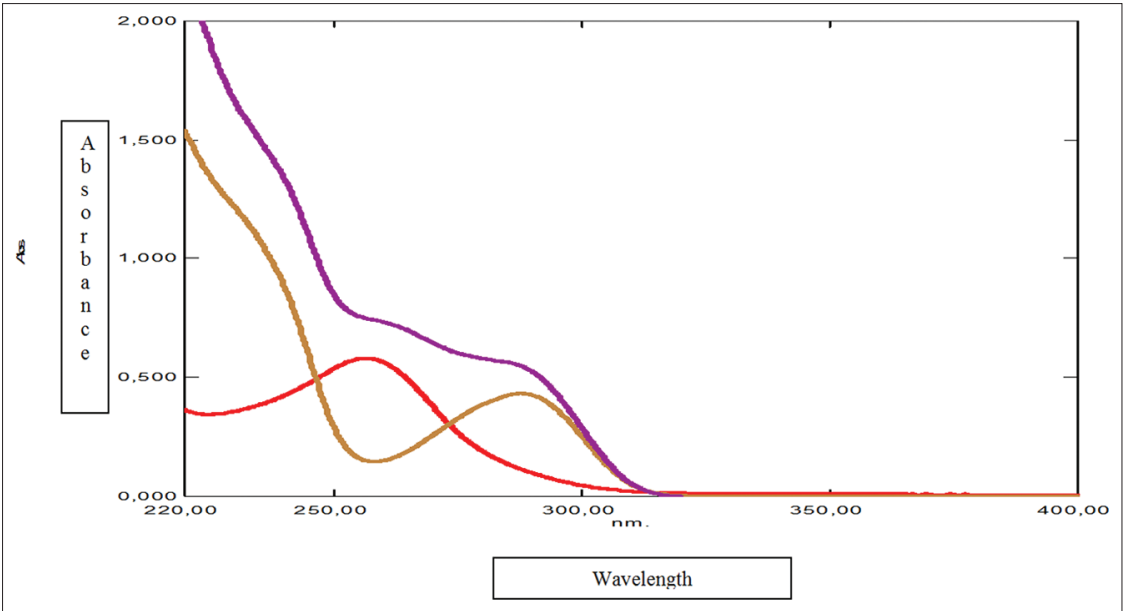

Fig. 12: Overlapping spectrum between $S$ commercial tablet with $8.2 \mathrm{mcg} / \mathrm{ml}$ sulfamethoxazole and $17.8 \mathrm{mcg} / \mathrm{ml}$ trimethoprim

Table 1: Result of determination of SLF and TRM levels on S commercial tablet with MCR

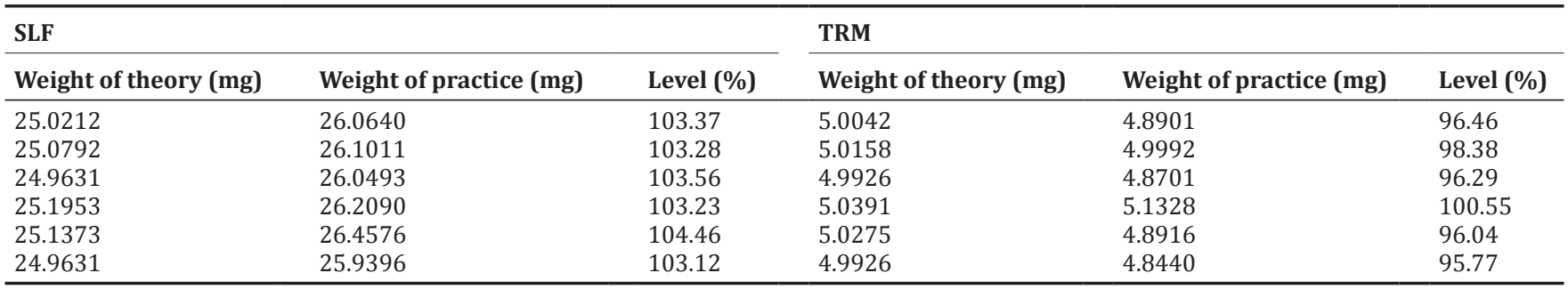

SLF: Sulfamethoxazole, TRM: Trimethoprim, MCR: Mean centering of ratio spectra 
Determination results of SLF and TRM in tablet preparations

The absorption spectra of the $\mathrm{S}$ commercial tablet sample and the overlapping spectra between samples with spectra of SLF and TRM are shown in Figs. 10 and 11.

In the preparation of the sample solution, first, the powder was weighed using ethanol $70 \% \pm 15 \mathrm{ml}$ until dissolved then sufficient with $0.1 \mathrm{~N} \mathrm{NaOH}$. The use of ethanol is to dissolve TRM because TRM is very difficult to soluble in water and ethanol according to Indonesia Pharmacopoeia $4^{\text {th }}$ edition (1995), but according to Moffat, TRM solubility is soluble in water 1:2500 and soluble in ethanol 1:300. This means that $1 \mathrm{~g}$ TRM in $300 \mathrm{ml}$ so with $15 \mathrm{ml}$ will be able to dissolve $50 \mathrm{mg}$ raw, and therefore, ethanol is used to help dissolve TRM because TRM is very difficult to dissolve in water so that by only using $\mathrm{NaOH} 0.1$ $\mathrm{N}$, it would not be dissolved. It because the composition of $0.1 \mathrm{~N} \mathrm{NaOH}$ is mostly water.

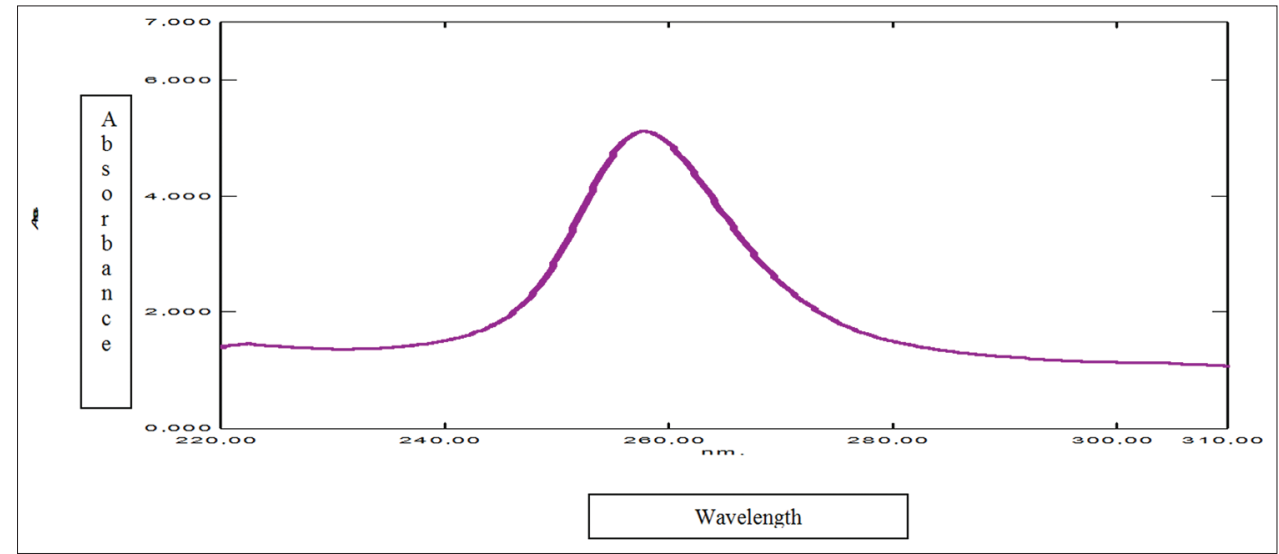

Fig. 13: Spectrum ratio of sulfamethoxazole on $S$ commercial tablet

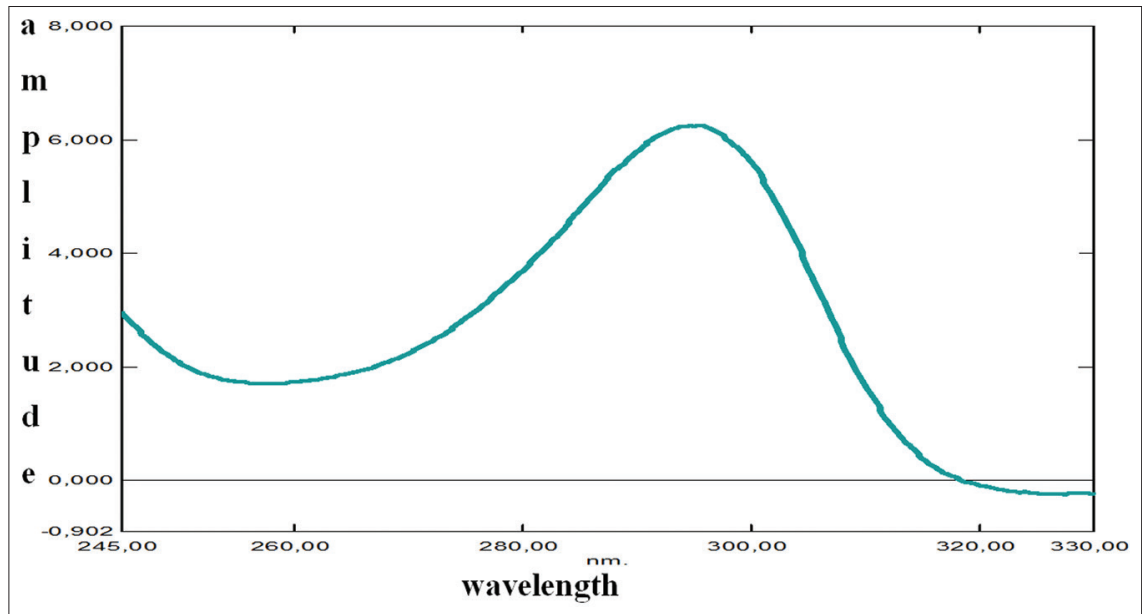

Fig. 14: Spectrum ratio of trimethoprim on tablet $S$ samples

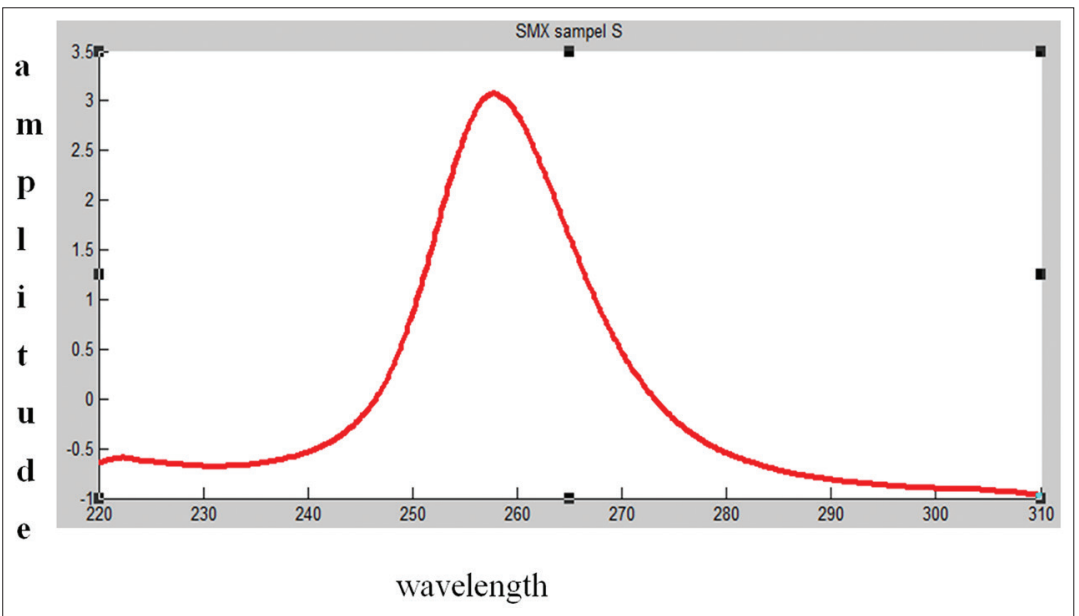

Fig. 15: Mean centering of ratio spectra of sulfamethoxazole on tablet $S$ 


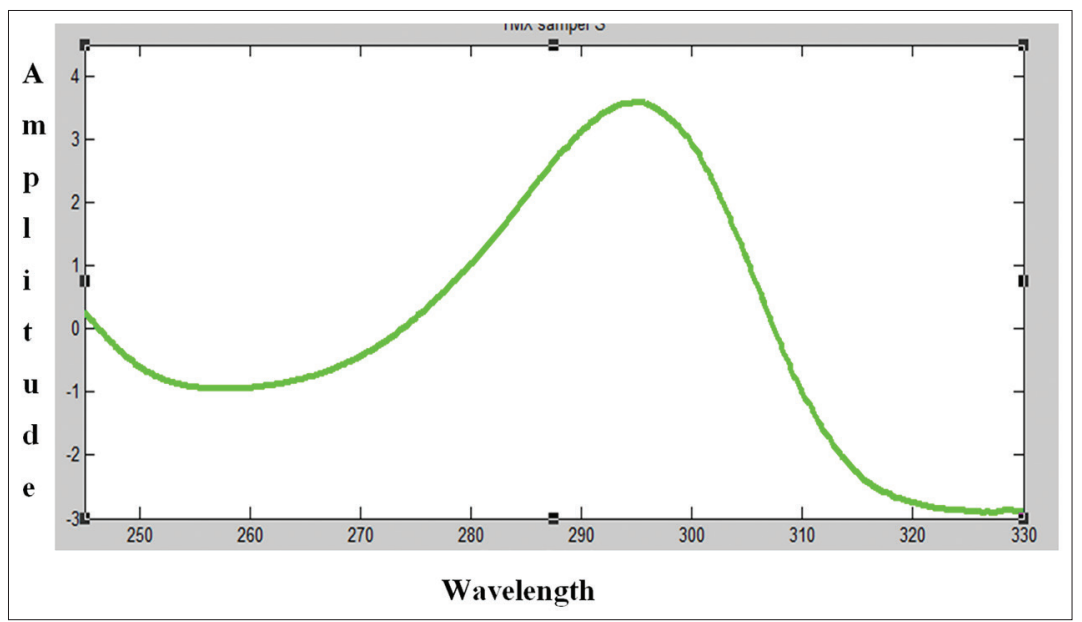

Fig. 16: Mean centering of ratio spectra of trimethoprim on $S$ commercial tablet

Table 2: The statistically determining of SLF and TRM Levels in S comercial tablet

\begin{tabular}{llll}
\hline Drug & $\begin{array}{l}\text { Level of } \\
\text { content }(\mathbf{m g})\end{array}$ & $\begin{array}{l}\text { Content in } \\
\text { etiquette } \mathbf{( m g )}\end{array}$ & $\begin{array}{l}\text { Terms of } \\
\text { content (\%) }\end{array}$ \\
\hline SLF & $(413.24 \pm 1.36)$ & 400 & $(93-107)$ \\
TRM & $(77.27 \pm 1.70)$ & 80 & $(93-107)$ \\
\hline
\end{tabular}

SLF: Sulfamethoxazole, TRM: Trimethoprim

Preparation of S commercial tablet solution was done by addition of standard solution method, because the concentration of TRM during measurement is too small so it needs to be use the standard addition method so that its TRM can be measured fulfill Lambert Beer's law.

The prepared and standardized samples were measured at a wavelength of 200-400 $\mathrm{nm}$ to obtain the sample spectrum of the S commercial tablet. Then, the spectrum was divided by a predetermined divisor to obtain the ratio spectrum of each drug. Then, the ratio spectra of the SLF and TRM are filtered by the MATLAB application to obtain the $\mathrm{MC}$ value, and then, calculated the rate obtained using the regression equation. Spectrum ratio of SLF and TRM on S commercial tablet can be seen in Figs. 13 and 14.

The spectrum of MCR, SLF, and TRM on tablet S can be seen in Figs. 15 and 16.

In determining the sample rate, it is taken the amplitude value at the maximum peak that has been directed and then inserted into the regression equation that has been obtained previously. The data of SLF and TRM levels on tablet S are summarized in Table 1, and the results of statistically determining SLF and TRM in S commercial tablets are given in Table 2.

The range of SLF and TRM levels on tablet S was 102.97-103.65\% and 94.45-98.71\%, respectively. These levels have fulfilled the requirements of the levels listed in Indonesia Pharmacopoeia $5^{\text {th }}$ edition

\section{CONCLUSION}

Based on the research, it can be concluded that:

1. The method of ultraviolet spectrophotometer on MCR can be used in the determination of SLF and TRM levels in tablet preparations

2. The SLF and TRM levels in tablet preparations fulfill the requirements of SLF and TRM mixed tablets based on Indonesia Pharmacopoeia $5^{\text {th }}$ edition $(93-107) \%$, while the content obtained on tablet $\mathrm{S}$ is $103.31 \pm 0.34 \%$ and $96.588+2.13 \%$

\section{CONFLICT OF INTEREST}

We declare that there is no conflict of interest.

\section{AUTHOR CONTRIBUTION}

1. The second author performs and discusses the results of data analysis

2. The third author prepares the implementation of the research procedure directed by the first author.

\section{REFERENCES}

1. Tjay TH, Rahardja K. Important Medicines: Benefits, Usage, and Side Effects. $6^{\text {th }}$ ed. Jakarta: PT Elex Media Komputindo; 2007. p. 143-4.

2. Ditjen BK. Indonesian Pharmacopoeia. $5^{\text {th }}$ ed. Jakarta: Kementerian Kesehatan RI; 2014.

3. Ditjen POM RI. Indonesian Pharmacopoeia. $4^{\text {th }}$ ed. Jakarta: Departemen Kesehatan RI; 1995.

4. Bhatia NM, Desai RB, Jadhav SD. Simultaneous estimation of losartan potassium and hydrochlorothiazide from tablets by first order derivative spectroscopy. Int J Pharm Pharm Sci 2013;5(1):464-6.

5. Vijay DC, Nejal MB, Mallika S, Pranav SS. Comparative evaluation of first order, absorbance ratio and bivariate spectrophotometric methods for determination of atovaquone and proguanil in pharmaceutical formulation malarone. Int J of Pharm and Pharm Sci 2015;7(9):165-171.

6. Afkhami A. Bahram M. Mean centering of ratio spectra as a new spectrophotometric method for the analysis of binary and ternery mixture. Elsevier 2005;66:715-20.

7. Abdelwahab NS, Nouruddin WA, Fatatry HM, Osman WM. Determination of thiomersal, lidocain and phenylelpherine in their ternary mixture. J Chrom Sep Tech 2013;4:1-6.

8. Hasan SA, Elzanfalu ES, Salem MY, E-Zeany BA. Mean centering of double divisor ratio spectra, a novel spectrophotometric method for analysis of ternary mixtures. Spectrochim Acta A Mol Biomol Spectrosc 2016;153:132-42.

9. Abdelrahman MM, Abdelaleem EA. Mean centering of ratio spectra and successive derivative ratio spectrophotometric methods for determination of isopropamide iodide, trifluoperazine hydrochlorida and trifluoperazine oxidative degradate. J Saudi Chem Soc 2016;20:S153- 6 .

10. Bhatt NM, Chavada VD, Sanyal M, Shrivastav PS. Manipulation ratio spectra for the spectrophotometric analysis of diclofenac sodium and pantoprazole sodium in laboratory mixtures and tablet formulation. Sci World J 2014;2014:495739.

11. Rúbia AS, Isabella CA, Aline MR, Adriano CM, Patrik OR, Anil KS, et al. Simultaneous determination of gatifloxacin and prednisolone acetate in ophthalmic formulation using first-order UV derivative spectroscopy. Arab J Chem 2017;10:604-10.

12. Kakhki RM, Bazi R. Application of mean centering spectra spectrophotometric method for simultaneous determination of salisylic acid and benzoic acid in fruit joice samples. Russ Agric Sci 2015;41:66- 70 . 
13. Moffat AC, Osselton MD, Widdop B. Clarke's Analysis of Drug and Poison. $4^{\text {th }}$ ed. London: Pharmaceutical Press; 2011. p. 2082-3, 2200-1.

14. Day RA, Underwood AL. Quantitative Analysis. $5^{\text {th }}$ ed. USA: PrenticeHall; 1986. p. 388-407.

15. Gandjar IG, Rohman A. Analysis of Drug Spectrophotometric and Chromatography. Yogyakarta: Pustaka Pelajar; 2012. p. 482-3.
16. Harmita $H$. Instructions and $\backslash$ implementation validation method and method calculation. Pharm Sci Mag Jakarta Indonesia 2004;1:117-35.

17. Rohman A. Pharmaceutical Chemistry. Yogyakarta: Pustaka Pelajar; 2007. p. 243.

18. Sudjana. Statistica Method. $6^{\text {th }}$ ed. Bandung: Penerbit Tarsito; 2005. p. 168 